\title{
A educação em direitos humanos no currículo escolar do município de Santo André
}

\author{
Education in human rights in the school curriculum of the Santo André' \\ municipality
}

\author{
iD Marina Aparecida Garrido \\ Mestre em Educação \\ Universidade Municipal de São Caetano do Sul - USCS \\ São Caetano do Sul - São Paulo- Brasil \\ marinagarrido028@gmail.com \\ Paulo Sérgio Garcia \\ Doutor em Educação \\ Universidade Municipal de São Caetano do Sul - USCS \\ São Caetano do Sul - São Paulo- Brasil \\ paulo.garcia@online.uscs.edu.br
}

Resumo: Este estudo analisou as diretrizes relacionadas à Educação em Direitos Humanos (EDH), voltadas para o Ensino Fundamental, presentes nos documentos curriculares do município de Santo André - São Paulo. Foi utilizada a abordagem qualitativa, a partir da análise de conteúdo. Os resultados mostraram que em que pese a presença de algumas diretrizes particularizadas, há um quadro visível de ausências de indicações que pode obstaculizar a formação dos alunos em relação à EDH. Neste contexto, as escolas podem ter concepções, ideias e projetos muito diversos para trabalhar o assunto ou, simplesmente, colocá-lo em um segundo plano. Tal processo pode dar origem a oportunidades de aprendizagem, em relação EDH, muito diferentes. De fato, enquanto alguns jovens poderão vivenciar uma cultura de tolerância, de paz, de solidariedade e de respeito aos direitos humanos, outros podem ficar com este direito restrito. Um processo que pode ser caracterizado como discriminação social. estes dados podem ser usados para fomentar as discussões do a EDH.

Palavras chave: educação em direitos humanos; ensino fundamental; anos iniciais; documentos curriculares; políticas educacionais.

Abstract: This study analyzed the guidelines related to Human Rights Education (HRE), aimed at Elementary School, present in the curriculum documents of the municipality of Santo André. A qualitative approach was used, based on the content analysis. The results showed that despite the presence of some specific guidelines, there is a visible framework of absences that can hinder the students' education related to HRE. In this context, schools may have quite different conceptions, ideas, and projects to work on the subject or, simply, put it in a second plan. This process can give rise to very different learning opportunities in relation to HRE. In fact, while some students may experience a culture of tolerance, peace, solidarity and respect for human rights, others may be left with this restricted right. A process that can be characterized as social discrimination. These data can be used to fuel discussions on the HRE.

Key-words: human rights education; elementary school; early years; curriculum documents; educational policies.

Cite como

\section{(ABNT NBR 6023:2018)}

GARRIDO, Marina Aparecida; GARCIA, Paulo Sérgio. A Educação em Direitos Humanos no currículo escolar do município de Santo André. Dialogia, São Paulo, n. 38, p. 1-17, e19605, maio/ago. 2021. Disponível em: https://doi.org/10.5585/38.2021.19605.

American Psychological Association (APA)

Garrido, M. A., \& Garcia, P. S. (2021, maio/ago.). A Educação em Direitos Humanos no currículo escolar do município de Santo André. Dialogia, São Paulo, 38, p. 1-17, e19605. https:// doi.org/10.5585/38.2021.19605. 


\section{Introdução}

A educação em Direitos Humanos propicia a formação de uma cultura de respeito à dignidade humana por meio, entre outras questões, da promoção e da vivência de valores, atitudes, hábitos e comportamentos que podem se transformar em práticas sociais.

De fato, como indicaram Costa e Reis (2009, p.70), a EDH fortalece o "respeito aos direitos e liberdades fundamentais do ser humano; ao pleno desenvolvimento da pessoa humana e sua dignidade; a prática da tolerância, do respeito à diversidade de gênero e cultura, da amizade entre todas as nações".

Segundo Candau (2007), a Educação em Direitos Humanos tem de favorecer a formação de sujeitos de direito, em nível pessoal e coletivo, articulando as dimensões ética, político-social e as práticas concretas.

A EDH é em sua essência a formação de uma cultura de transformação, de respeito à dignidade humana, por meio da promoção e da vivência dos valores de liberdade, de justiça, de igualdade, de solidariedade, de cooperação, de tolerância e de paz. Ela tem como propósito promover, entre outras questões, atitudes e habilidades que possam encorajar a autoconfiança, que é parte da formação dos cidadãos.

Candau (2007, p. 61) considera a Educação em Direitos Humanos como ferramenta fundamental para a efetivação da democracia. Para a autora, ela é fundamental para o “desenvolvimento dos direitos humanos; 2. deve articular as categorias da igualdade e da diferença; 3. deve realizar o empoderamento dos atores sociais; 4. é uma filosofia e deve integrar a cultura escolar.

A Educação em Direitos Humanos é uma educação necessariamente voltada, entre outras questões, para a conscientização sobre os Direitos Humanos, propondo uma formação baseada em valores. Neste sentido, ela tem de ser baseada em mudanças no cotidiano escolar e necessita ser compartilhada por todos os envolvidos no processo educacional, sejam eles, gestores, diretores, coordenadores, docentes, entre outros.

Como indicou Mota (2020, p. 1129) "educar em direitos humanos é reconhecer que não basta teorizar e discursar sobre direitos humanos, é necessário praticar, respeitar e defender os direitos humanos no cotidiano”. A autora reconhece a importância do tema para a Educação Básica.

Vários documentos foram criados trazendo diretrizes em relação à EDH. Entre eles, o Plano Nacional de Educação em Direitos Humanos (PNEDH), publicado no ano de 2008, e, mais recentemente, a Base Nacional Comum Curricular (BNCC), documento obrigatório para os 
municípios e estados elaborarem seus currículos. Algumas áreas dentro da BNCC trazem indicações em relação à Educação em Direitos Humanos.

Todavia, a EDH ainda necessita avançar e integrar espaços tanto da educação formal como não-formal. Ao mesmo tempo, outro desafio se relaciona à formação de professores para atuar sobre o tema. Há ainda duas outras questões que necessitam de reflexão. A primeira é a constante violação dos Direitos Humanos com o crescimento das políticas neoliberais que promovem e mantem a desigualdade social (SILVA, 1999); a segunda é o novo quadro de narrativas e práticas da extrema-direita que se opõe as convicções relacionadas aos Direitos Humanos.

Considerando a importância da Educação em Direitos Humanos, sua presença em documentos mandatórios no Brasil (BNCC) e este novo quadro de narrativas, este estudo analisou as diretrizes relacionadas à Educação em Direitos Humanos, voltadas para o Ensino Fundamental, presentes nos documentos curriculares do município de Santo André. Trata-se de um município com altos níveis socioeconômicos e educacionais.

\section{Educação em direitos humanos: uma perspectiva histórica e documental}

A Organização das Nações Unidas (ONU) indicou que os Direitos Humanos são essenciais para proteger as pessoas e os grupos sociais contra ações, daqueles que desrespeitam a dignidade da pessoa humana.

Para Bobbio (2004), os Direitos humanos são construções históricas com as marcas das contradições da realidade. Eles são nascidos em certas conjunturas, baseadas nas lutas em defesa de novas liberdades contra velhos poderes. Castilho (2011, p. 11), indicou que "a expressão direitos humanos representa o conjunto das atividades realizadas de maneira consciente, com o objetivo de assegurar ao homem a dignidade e evitar que passe por sofrimentos".

As origens dos Direitos Humanos têm raízes na França, em 1789, na Revolução Francesa, quando deputados na Assembleia Nacional discutiram sobre a criação de uma Declaração dos Direitos do Homem e do Cidadão, orientada pelos ideais de liberdade, igualdade e fraternidade.

Comparato (2015) indicou que, com a aprovação de dezessete artigos, esta Declaração deu maior soberania ao povo, retirando-a do rei. A partir dela, todos passaram a ser considerados iguais perante a lei, sem que alguns tivessem privilégios de origem. Esse documento, por sua importância, inspirou a Declaração Universal dos Direitos Humanos, criada depois da segunda Guerra Mundial pelas grandes potências. O artigo primeiro da Declaração trouxe que "todos os seres humanos nascem livres e iguais em dignidade e direitos. São dotados de razão e consciência e devem agir em relação uns aos outros com espírito de fraternidade.” (ONU, 1948). 
Em 1993, a Organização das Nações Unidade (ONU) realizou o Congresso Internacional sobre Educação com o tema dos Direitos Humanos e Democracia, estabelecendo o Plano Mundial de Ação para a Educação em Direitos Humanos. Esse plano tinha como propósito assumir o compromisso de realizar uma educação para a tolerância e para o respeito, para dignidade da pessoa e para democracia. Tal compromisso, de realizar uma educação para a tolerância e para o respeito, foi ratificado na Conferência de Viena, em 1993, que indicou a inclusão nos currículos de conteúdos relacionados aos Direitos Humanos, na Educação em Direitos Humanos.

A Educação em Direitos Humanos tem suas raízes mais consolidadas a partir de 1948, quando a ONU adotou a Declaração Universal dos Direitos Humanos, que orienta os Direitos Humanos básicos. Em 1994, a ONU declarou a década para a Educação em Matéria de Direitos Humanos (1995-2004). Em 2004, foi criado o Programa Mundial para a Educação em Direitos Humanos (PMEDH), primeira fase. Em 2010, o PMEDH, segunda fase, para a educação superior.

No Brasil, a Constituição Federal (CF/88), aprovada em 22 de setembro de 1988, em meio à luta contra a ditadura civil-militar (1964-1985), período marcado pela violação dos direitos de liberdade, assegura os direitos de igualdade, entre outros. $\mathrm{O}$ artigo $6^{\circ}$ da $\mathrm{CF} / 88$ definiu a educação como direito social, dentre outros direitos como saúde, moradia, trabalho, entre outros. Além disso, seu art. 205 prescreve que "a educação, direito de todos e dever do Estado e da família, será promovida e incentivada com a colaboração da sociedade, visando ao pleno desenvolvimento da pessoa, seu preparo para o exercício da cidadania e sua qualificação para o trabalho" (BRASIL, 1988, p. 35).

A Lei no 9.394/1996 (LDBEN/96), que reconhece o direito à educação básica como direito público subjetivo, indicou que os conteúdos associados aos Direitos Humanos devem ser incluídos, como temas transversais, nos currículos.

Os Parâmetros Curriculares Nacionais (PCN), publicados na década de 1990, trouxeram um conjunto de diretrizes a fim de, entre outras questões, buscar a coesão no sistema educacional de forma a orientar ações educativas para o ensino obrigatório e propor, assim, melhorias para a educação nacional nas escolas brasileiras.

Como forma de garantir respeito às diversidades culturais, regionais, étnicas, religiosas e políticas presentes na sociedade brasileira, os PCN trouxeram uma proposta flexível e aberta, a fim de que a educação possa, a partir da flexibilidade e do diálogo, atuar no processo de construção da cidadania das crianças e dos jovens brasileiros.

A partir de questões sociais relevantes, que demonstraram abrangência nacional e até mesmo de caráter universal, outros assuntos foram incorporados na proposta educacional dos 
PCN como os temas transversais. Entre eles pode-se encontrar a ética, o meio ambiente, a saúde, a pluralidade cultural e a orientação sexual.

Os temas transversais na educação estão voltados para a compreensão e para a construção da realidade social, dos direitos e das responsabilidades relacionados com a vida pessoal e coletiva e com a afirmação do princípio da participação política. Isso significa que devem ser trabalhados, de forma transversal, nas áreas e/ou disciplinas já existentes. Entre os temas transversais, dois assumem grande importância no cenário da EDH: a ética e a pluralidade cultural.

O grande desafio da escola, neste contexto, é investir na superação da discriminação e atuar na diversidade etnocultural que compõe o patrimônio sociocultural brasileiro, valorizando a trajetória particular dos grupos que compõem a sociedade. Nesse sentido, a instituição escolar deve ser local de diálogo, para se aprender a conviver, vivenciando a própria cultura e respeitando as diferentes formas de expressão cultural.

Ainda no contexto das indicações legais, em 2004 foi aprovada pelo Conselho Nacional de Educação (CNE) e homologada pelo Ministério da Educação (MEC), no mesmo ano, as Diretrizes Curriculares Nacionais para a Educação das relações Étnico-Raciais Raciais e para o Ensino de História e Cultura Afro-Brasileira e Africana. Trata-se de diretrizes e princípios para subsidiar o planejamento, as práticas e a avaliação no cenário educacional buscando formar um jovem atuante, crítico e transformador.

Em 2008, foi elaborado o Plano Nacional de Educação em Direitos Humanos (PNEDH), que afirma o compromisso nacional sob a forma de políticas públicas de EDH. O documento traz os princípios norteadores da Educação em Direitos Humanos na educação básica:

a) a educação deve ter a função de desenvolver uma cultura de Direitos Humanos em todos os espaços sociais; direitos humanos e cultura escolar; b) a escola como espaço privilegiado para a construção e consolidação da cultura de Direitos Humanos, deve assegurar que os objetivos a serem adotados sejam coerentes com os valores e princípios da educação em Direitos Humanos; c) a educação em Direitos Humanos, por seu caráter coletivo, democrático e participativo, deve ocorrer em espaços marcados pelo entendimento mútuo, respeito e responsabilidade; d) a educação em Direitos Humanos deve estruturar-se na diversidade cultural e ambiental, garantindo a cidadania, o acesso ao ensino, permanência e conclusão, a equidade(étnico-racial, religiosa, cultural, territorial, físico-individual, geracional, de gênero, de orientação sexual, de opção política, de nacionalidade, dentre outras) e a qualidade da educação; e) a educação em Direitos Humanos deve ser um dos eixos fundamentais da educação básica e permear o currículo, formação inicial e continuada dos profissionais da educação o projeto políticopedagógico da escola, os materiais didático--pedagógicos, o modelo de gestão e a avaliação; f) a prática escolar deve ser orientada para a educação em Direitos Humanos, assegurando o seu caráter transversal e a relação dialógica entre os diversos atores sociais. (BRASIL, 2008, p.32). 
O PNEDH foi uma importante conquista para a educação brasileira, pois o seu processo de discussão, elaboração e implementação foi acompanhado de processos democráticos de discussão das políticas públicas, por meio de conferências abertas para discussão de temáticas educacionais. As diretrizes do PNEDH ampliaram a discussão em torno da participação dos cidadãos nas questões voltadas para as políticas públicas educacionais. Assim, a EDH pode estar presente de forma articulada aos componentes curriculares, nas atividades de pesquisa, nas artes, nas linguagens, na própria organização do espaço e do tempo escolar, no respeito cotidiano às diferenças.

Em 2017, foi promulgada a Base Nacional Comum Curricular, que não se constitui um currículo, mas indicações gerais e claras para que os municípios e os estados construam suas propostas curriculares. O documento traz várias orientações para a Educação em Direitos Humanos. Na área de Ciências Humanas, segundo a BNCC (2017), deve-se estimular uma formação ética, essencial para a formação das novas gerações, ajudando os jovens na construção de um sentido de responsabilidade para que eles valorizem: “[...] os Direitos Humanos; o respeito ao ambiente e à própria coletividade; o fortalecimento de valores sociais, tais como a solidariedade, a participação e o protagonismo voltados para o bem comum; e, sobretudo, a preocupação com as desigualdades sociais. (p. 352).

Todavia, toda esta construção, um compromisso com os Direitos Humanos a partir de legislações, foi abalada pelo governo de Bolsonaro, com mudanças, sobretudo em três grandes áreas. O Ministério dos Direitos Humanos $(\mathrm{MDH})$ foi extinto como instituição autônoma e tem sido integrado ao Ministério das Mulheres e da Família. O Ministério da Educação (MEC), já teve 3 Ministros, em praticamente 6 meses de governo, em virtude das divergências dos programas anteriores e da inexperiência com a complexidade da pasta. O Ministério das Relações Exteriores (MRE) mudou suas diretrizes e, neste contexto, ameaçou até mesmo abandonar acordos internacionais como o de Paris. Essas transformações atingiram de forma direta os Direitos Humanos e à Educação em Direitos Humanos, inviabilizando, entre outras questões, o Plano Nacional em Direitos Humanos.

Em vários países, como EUA, Turquia, Itália, Noruega, Hungria e Brasil, o crescimento do poder de grupos de extrema-direita escandaliza em virtude de discursos públicos que procuram descontruir os Direitos Humanos. Uma desconstrução, de grupos extremistas conservadores, baseada no discurso do ódio, em fake-news e na depreciação da democracia, entre outras questões. Todavia, não se pode isentar do debate nações como Venezuela, Cuba, Grécia e Rússia, marcadas 
por populismos e ditaduras de esquerda que, em alguns casos, são tão autoritárias como a direita. Apesar de não agredirem Direitos Humanos, com suas narrativas, eles são ocultados ou negados.

No caso do Brasil, a extrema-direita - ultra-direita ou ultra-liberais -, que estão no poder, possui discursos e posicionamentos políticos radicais, criminalizam a pobreza, fazem uso de um nacionalismo xenófobo, atuam no desmonte da Educação Pública brasileira, entre outras questões. Um quadro nítido que descaracteriza e afronta os Direitos Humanos e a Educação em Direitos Humanos.

\section{A educação em direitos humanos no contexto escolar}

Gorzevski e Touchen (2008) defendem que a Educação em Direitos Humanos é fundamental para a formação intelectual e cultural sobre a dignidade humana. Tal formação ocorre pela vivência de atitudes e valores como igualdade, tolerância e paz.

Para Silva (2016), uma educação comprometida com a emancipação e baseada nos Direitos Humanos tem suas bases sobre a conscientização das pessoas e na tomada de responsabilidades diante das situações de opressão, de exclusão social e política. Para Almeida e Reis (2018, p. 56), a $\mathrm{EDH}$ poderá ser considerada legítima quando for capaz, entre outras coisas, de "sensibilizar, incentivar o diálogo, revelar horizontes de possibilidades, promover uma abertura em direção ao outro, estimular o pensamento e a indignação ante toda forma de opressão.”

A Educação em Direitos Humanos colabora para formar cidadãos críticos e propõe mudanças na escola, no currículo e na sala de aula. Neste sentido, Candau (1998, p. 36) destaca o aspecto sociocrítico da educação, quando afirma que a EDH "potencializa uma atitude questionadora, desvela a necessidade de introduzir mudanças, tanto no currículo explícito, quanto no currículo oculto, afetando assim a cultura escolar e a cultura da escola."

A Educação em Direitos Humanos deve ter um caráter permanente, contínuo e compartilhado, e deve ser assumida por aqueles que estão envolvidos no processo educacional. $\mathrm{Na}$ escola, tem de ser trabalhada de forma transversal e interdisciplinar, com a participação de várias disciplinas, professores e demais profissionais da escola. Ela é uma empreitada coletiva. De fato, a escola é um espaço particularmente especial para transformação e para a construção de uma sociedade justa para todos. No contexto escolar, crianças e jovens podem vivenciar, aprender e valorizar os valores culturais e a diversidade.

Benevides (2007, p. 01) acrescenta indicando que a EDH tem de ser "compartilhada por aqueles que estão envolvidos no processo educacional - os educadores e os educandos - ou ela não será educação e muito menos educação em direitos humanos". 
É essencial que os conhecimentos trabalhados na escola sobre a Educação em Direitos Humanos sejam práticos, colaborativos, permanentes e estejam ligados aos cotidianos dos alunos. Como indicaram Almeida e Reis (2018), eles não devem ser apenas teóricos e necessitam estar relacionados ao cotidiano dos jovens.

Essas questões podem ser efetivadas na escola e na sala de aula, sobretudo a tomada de consciência, por meio da vivência de situações e de uma prática coerente com a emancipação. No entanto, é necessário que a EDH não fique somente atrelada à disciplina de História, a partir, entre outras questões, do estudo da História e Cultura Afro-Brasileira e Indígena.

A Educação em Direitos Humanos tem de ser referenciada pelo coletivo escolar. Trata-se de um trabalho participativo e colaborativo entre as disciplinas, os professores e as famílias. Segundo Almeida e Reis (2018, p. 55), para a EDH é fundamental a articulação dos conhecimentos proveniente da interdisciplinaridade, pois permite a criação de novas experiências metodológicas entre as diversas áreas do saber. $\mathrm{O}$ envolvimento dos professores possibilita o diálogo e a formulação de experiências no interior das salas de aula e fora delas.

Soveral (2011) indicou que há a necessidade urgente do desenvolvimento de uma prática pedagógica na perspectiva na Educação em Direitos Humanos desde as séries iniciais, em todas nossas escolas, para que os estudantes passem a viver seus direitos e deveres.

Desta forma, educar em Direitos Humanos, desde as séries iniciais, é um trabalho para formar jovens participativos e críticos, que digam não a qualquer forma de exclusão social ou cultural. De acordo com Melo Filho (2015, p. 36), não se pode ter como sustentação "a construção de indivíduos adaptados, mas exatamente seu oposto, a formação de atores combativos contra a lógica liberal capitalista, aos princípios da exploração, da exclusão e da equalização/uniformização de mentalidades e valores."

A EDH revela-se igualmente importante no contexto escolar, devido ao crescente aumento do bullying, das situações de indisciplina, da violência, das agressões, dos insultos, da falta de respeito, entre outros. As situações de violência nas escolas, entre outras, já motivaram a criação, em 2015, da Lei n. 13.185, de 6 de novembro de 2015, que estabelece o Programa de Combate à Intimidação Sistemática (Bullying).

\section{O município de Santo André}

O município de Santo André está localizado entre o Planalto Paulista e a escarpa da Serra do Mar e possui uma área de 174,38 km², ou 0,07\% do território do estado de São Paulo. Localizase na Região Metropolitana de São Paulo (RMSP), a $18 \mathrm{~km}$ da capital paulista e integra a região do 
ABC com os municípios de Diadema, Mauá, Ribeirão Pires, Rio Grande da Serra, São Bernardo do Campo e São Caetano do Sul.

A cidade de Santo André possui elevados índices sociais, econômicos e educacionais. Seu Índice de Desenvolvimento Humano Municipal (IDH-M) é de 0,815 (ATLAS DO DESENVOVILMENTO HUMANO, 2019) e no ranking dos municípios brasileiros, o município ocupa a $14^{\mathrm{a}}$ posição entre os 5.565 municípios.

Santo André tem uma área em constante desenvolvimento. Com uma população de 676.407 registrada, no último censo de 2010, e uma com estimativa de 715.231, para o ano de 2017, a cidade tem uma densidade demográfica de 3.848,01 hab. $/ \mathrm{km}^{2}$, de acordo com dados. (IBGE, 2019).

A cidade dispunha, em 2019, de 84 escolas estaduais de ensino fundamental e médio e 87 particulares dos mesmos segmentos. Há diversas instituições de ensino superior, que oferecem cursos de graduação e pós-graduação em diversas áreas. Em 2004, foi instalado o campus da Universidade Federal do ABC (UFABC). Santo André possui também um Teatro Municipal, Museus, Parques Públicos, entre outros equipamentos.

De acordo com dados de 2019 da Secretaria de Educação, a rede educacional do município atende 34.848 alunos na faixa etária de 0 a 10 anos (16.827 alunos na Educação Infantil e 18.021 alunos nos anos iniciais do Ensino Fundamental, não sendo inclusa a Educação de Jovens e Adultos). Na Educação Infantil, 7.871 alunos estão matriculados na creche e 8.956 na pré-escola.

\section{Metodologia}

Este estudo analisou as diretrizes relacionadas à Educação em Direitos Humanos, voltadas para o Ensino Fundamental, presentes nos documentos curriculares do município de Santo André.

Segundo Chizzotti (2003), a pesquisa qualitativa possibilita algumas formas de investigação e diferentes procedimentos técnicos de coleta. A opção por esta metodologia, nesta presente pesquisa, está atrelada a sua abordagem aberta e flexível, já que se pretende realizar uma análise de diretrizes, inseridas em documentos.

A pesquisa contou com as diretrizes da análise de documentos. Neste caso, como indica Gil (2002, p. 45), este tipo de pesquisa, além de se assemelhar a pesquisa bibliográfica, usa "materiais que não receberam ainda um tratamento analítico, ou que ainda podem ser reelaborados de acordo com os objetos de pesquisa". 
O material utilizado na pesquisa documental pode estar associado a revisões bibliográficas e ser avaliado a partir da interpretação dos objetivos. Este tipo de estudo apresenta dois tipos de fontes: aquelas que são denominadas de primárias, documentos originais e oficiais, e as secundárias, aquelas provenientes da literatura referente ao documento.

Neste estudo foram analisados os "Documentos Curriculares da Rede Municipal de Ensino de Santo André", volume 1 e 2, publicados no ano de 2019. As apreciações nos documentos ocorreram a partir da análise de conteúdo, utilizando as orientações de Bardin (1977), Franco (2012) e Flick (2013), autores que realizaram contribuições significativas nesta área.

Bardin (1977) indicou que existem três etapas para a análise de conteúdo. Segundo a autora, a primeira está vinculada à pré-análise; a segunda, à exploração do material; e a terceira, ao tratamento dos resultados. Para Flick (2013, p. 137-138) também existem três etapas. A primeira etapa atrela-se à definição do material a ser utilizado, considerando que o mesmo, para se tornar relevante, deverá responder ao problema de pesquisa. Na segunda, o pesquisador se preocupara em analisar a coleta de dados, se atentando a questões do tipo: "como o material foi gerado", "quem estava envolvido", "de onde vieram os documentos a serem analisados" (Idem). Na terceira, é necessário realizar uma análise das informações, categorizá-las e interpretá-las.

Resultados e discussão: A Educação em Direitos Humanos nos Documentos Curriculares de Santo André

Santo André construiu três documentos curriculares, que foram lançados no ano de 2019. De acordo com Santos (2019, p. 82), o início da elaboração dos documentos buscou um alinhamento da rede de ensino, no início de 2017 a partir das análises dos planos de ensino dos professores.

A elaboração dos documentos envolveu professores, gestores e profissionais da educação. Foram realizadas várias reuniões, eventos e conferências, em um movimento que durou dois anos. Dos três documentos elaborados, os dois primeiros tratam da Educação Básica e o terceiro da modalidade de Educação de Jovens e Adultos.

Todos os documentos foram aprovados pelo Conselho Municipal de Educação de Santo André, mediante Parecer 003/2019, complementado pela Indicação 002/2019, com homologação da senhora Secretária de Educação em 17 de dezembro de 2019, conforme indicado na Lei de $\mathrm{n}^{\circ}$ 9.723/2015 de 20 de julho de 2015, meta 7, estratégia 7.2.

O primeiro documento, com 64 páginas e três partes, traz, na primeira parte, a concepção de Educação Básica da rede municipal de ensino, na segunda as indicações sobre a avaliação 
institucional e na terceira as sinalizações quanto à avaliação de sistema. Seus objetivos estão associados à caracterização teórica dos documentos, assumidos na rede municipal de Santo André.

O tema Educação em Direitos Humanos aparece pela primeira vez, na página 28, indicando para as escolas que é necessário assegurar a realização de um ambiente que promova "experiências positivas no sentido de aceitar a diversidade de saberes, de histórias e de questões estéticas, mediante experiências que façam sentido na vida dos sujeitos, prezando pela igualdade racial e os direitos humanos" (DCRMSAvi, p. 28-29). O fim deste mesmo texto indica ainda que é preciso prezar "pela igualdade racial e os direitos humanos" (p. 29).

De fato, tratam-se indicações valiosas, todavia, muito amplas, com pouca especificidade, o que deixa em aberto para os profissionais que atuam nas escolas o entendimento do que significa "prezar pela igualdade". No entanto, como indicou Candau (1998), a Educação em Direitos Humanos tem de ser descrita de forma clara para fortalecer uma atitude questionadora, de mudanças no currículo e tem de incidir sobre a cultura escolar e a cultura da escola.

Para Candau (2013), a Educação em Direitos Humanos necessita atuar para mudar atitudes, comportamentos e processos escolares. Tem de ter a participação de diferentes atores, individuais e coletivos, propiciando experiências em que se vivenciem os Direitos Humanos.

Assim, entende-se que tais diretrizes presentes neste documento curricular, primeiro volume, são demasiadamente tímidas e sem muitas especificidades para lidar com a importância da Educação em Direitos Humanos.

O segundo volume com 366 páginas, traz as "Abordagens pedagógicas para Educação Infantil e Ensino Fundamental ligadas à concepção de Educação Básica rede municipal de ensino”. As apreciações recaíram, sobretudo sobre a etapa de Ensino Fundamental. Este documento apresenta os objetos de conhecimentos e as habilidades que serão desenvolvidas nos jovens ao logo do Ensino Fundamental.

As análises revelaram que não existe nenhuma menção direta a Educação em Direitos Humanos em todo o documento, embora o PNEDH apareça nas referências. O tema é abordado em alguns outros assuntos e disciplinas (história), o que pode indicar, por exemplo, pouca discussão sobre ele na elaboração da proposta curricular, falta de conhecimento sobre o assunto ou de importância atribuída ao tema.

Apesar da relevância do tema, não há uma seção, projeto ou programa para tratar especificamente da Educação em Direitos Humanos. Infere-se que as escolas é que devem, se assim entenderem, trabalhar o tema e da forma que considerarem mais pertinente. 
O fato de não aparecerem diretrizes diretas quanto à Educação em Direitos Humanos é interessante, pois no início do volume, página 09, são indicados quais foram os documentos utilizados para a elaboração da proposta curricular e, entre eles, consta o Programa Nacional de Direitos Humanos. Este programa traz, no Eixo Orientador V, a indicação clara em relação à Educação em Direitos Humanos.

O Programa Nacional de Direitos Humanos (PNDH, 2010, p. 150) sinaliza que:

A educação e a cultura em Direitos Humanos visam à formação de nova mentalidade coletiva para o exercício da solidariedade, do respeito às diversidades e da tolerância. Como processo sistemático e multidimensional que orienta a formação do sujeito de direitos, seu objetivo é combater o preconceito, a discriminação e a violência, promovendo a adoção de novos valores de liberdade, justiça e igualdade.

Quanto à Educação em Direitos Humanos na Educação Básica, o Programa Nacional de Direitos Humanos (PNDH, 2010, p. 150) indica que:

Na educação básica, a ênfase é possibilitar, desde a infância, a formação de sujeitos de direito, priorizando as populações historicamente vulnerabilizadas. A troca de experiências de crianças de diferentes raças e etnias, imigrantes, com deficiência física ou mental, fortalece, desde cedo, sentimento de convivência pacífica. Conhecer o diferente, desde a mais tenra idade, é perder o medo do desconhecido, formar opinião respeitosa e combater o preconceito, às vezes arraigado na própria família.

As análises indicaram que o tema, Educação em Direitos Humanos, fica circunscrito a alguns componentes curriculares, sobretudo o de História. Todavia, a EDH, que se posiciona de forma crítica sobre as formas de opressão e de dominação presentes em nosso passado histórico, tem de ser estudada de forma ampla e interdisciplinar, pois ela é essencial na escola para ampliar as responsabilidades sociais dos alunos.

Nas apreciações do documento foram encontrados alguns objetos de conhecimento, na disciplina de história, como pluralidade cultural (raça, etnia, gênero, sexualidade), Estatuto da Criança e do Adolescente (ECA), cultura afro-brasileira (Lei n ${ }^{\circ}$ 10.639/2003), cultura indígena (Lei $n^{\circ}$ 11.645/2008), que são estudados em praticamente todos os anos do Ensino Fundamental.

Há uma preocupação válida para que o aluno, do Ensino Fundamental, anos iniciais, conheça as culturas afro-brasileira e indígena, aquelas que sofreram ao longo dos anos processos de dominação e de discriminação. Nota-se também a preocupação para que o jovem compreenda a pluralidade das culturas, como elemento constitutivo das diferenças sociais; conheça o Estatuto 
da Criança e do Adolescente, com seu conjunto de normas que tem como objetivo a proteção integral da criança e do adolescente. De fato, este documento é um marco legal e regulatório dos Direitos Humanos.

As habilidades, presentes no documento e na mesma disciplina, são mais diversificadas e ligadas a um conjunto de vivências a serem realizadas pelos alunos. Essas práticas (vivências), que devem ser realizadas pelos alunos se atrelam, sobretudo, a identificar contextos, conhecer, reconhecer e respeitar a diversidade (sociocultural, política, étnico-racial e de gênero), interpretar criticamente e reconhecer aspectos importantes da história e das culturas afro-brasileira e indígena e seus impactos sociais na contemporaneidade, reconhecer os direitos e deveres das crianças, entre outras.

Observa-se que as habilidades, que se atrelam, em geral, a uma capacidade para "fazer algo", para realizar uma atividade ou lidar com uma situação específica, são voltadas para o desenvolvimento dos objetos de conhecimento na prática.

De fato, esses objetos de conhecimento e essas habilidades são relevantes para serem trabalhadas com os alunos de Ensino Fundamental, anos iniciais, pois permitem, se bem organizados pelos professores, que os jovens aprendam sobre processos relacionados ao respeito pelas diferenças; que compreendam sobre aspectos atrelados à dominação, entre outras, dos povos europeus sobre outras nações, onde estão embutidas as questões de poder, de autoridade, de colonização, de racismo, de sexo e de gênero; que entendam sobre os elementos de discriminação atrelado à raça e etnia, à religião, sexo/gênero, peso, deficiência, estatura, condições de emprego, orientação sexual e idade.

Todavia, ressalta-se que é colocado um "peso" muito grande, ou seja, ênfase quase que exclusiva, sobretudo em um componente curricular, o de História. É nesta disciplina que aparecem a quase totalidade das referências em relação à Educação em Direitos Humanos. Todavia, Oliveira (2012, p. 593) indicou que a Educação em Direitos Humanos deve estar presente "em todas as matérias dos currículos das instituições de ensino, formal e informal, como fundamento do Estado Democrático de Direito, de forma a influir na formação de uma cidadania crítica e transformadora da realidade”. Ela deve ser transversal, contando com a participação de todos os componentes curriculares. A EDH precisa ser participativa, com a atuação de todos na escola e ter caráter interdisciplinar.

Na Educação em Direitos Humanos, a interdisciplinaridade é essencial, pois permite a articulação dos componentes curriculares, o diálogo entre os professores, a criação de projetos que podem ocorrer dentro das salas de aula. Para Candau e Scavino (2010), as estratégias metodológicas 
para a realização da EDH necessitam ser elaboradas a partir do diálogo, privilegiando a atividade, a participação e a realidade social dos alunos envolvidos no processo de ensino-aprendizagem.

Tal situação sugere o uso de diferentes linguagens e a promoção do diálogo entre diversos conhecimentos nos processos formativos dos alunos, para que eles compreendam de forma mais global e multidimensional sobre as possibilidades dos Direitos Humanos na vida das pessoas. Para a EDH se concretizar é necessário, entre outras questões, a formação de uma cultura para influenciar, compartilhar e mudar mentalidades, costumes, atitudes e comportamentos preconceituosos.

Por fim, destaca-se na análise dos documentos que não foram encontradas diretrizes, por exemplo, para o desenvolvimento de uma cultura da paz nas escolas, tão necessária nos tempos atuais. No entanto, a Educação em Direitos Humanos, segundo Oliveira (2012, p. 593), como fundamento do Estado Democrático de Direito, tem de incidir "na formação de uma cidadania crítica e transformadora da realidade, promovendo uma cultura da paz, da tolerância mútua, da solidariedade e de respeito aos direitos humanos e liberdades fundamentais."

A Lei n ${ }^{\circ}$ 13.663, do ano de 2018, também indicou que as escolas devem estabelecer ações, atividades, projetos que possam promover a cultura de paz, transformando o ambiente escolar em espaço de vivência livre de qualquer tipo de violência.

Por fim, também não foram encontradas diretrizes nos documentos para o combate ao bullying escolar. No entanto, estudos mostraram o crescente aumento da frequência de situações de indisciplina, agressões físicas e verbais, desobediência às regras, bullying, violência, entre outros, no contexto escolar (LEME, 2006; AQUINO, 2011; ABRAMOVAY, 2016).

Sintetizando as análises aqui realizadas, indica-se que os documentos curriculares traziam objetivos, fundamentação teórica e qualidade textual. Todavia, o tema Educação em Direitos Humanos não aparece de forma explicita e é desenvolvido, principalmente, na disciplina de História.

\section{Considerações Finais}

Este estudo analisou as diretrizes relacionadas à Educação em Direitos Humanos, voltadas para o Ensino Fundamental, presentes nos documentos curriculares do município de Santo André. Foi possível reunir elementos empíricos que demostraram a ausência de indicações diretas do tema para as escolas, apesar de os documentos possuírem organização clara, com objetivos declarados e fundamentação teórica atual. 
Tal ausência do tema Educação em Direitos Humanos, de forma explicita nos documentos, apenas com algumas indicações, objetos de conhecimento e habilidades sendo abordados, sobretudo, na disciplina de História, pode ser considerada preocupante para o desenvolvimento de temas relacionados ao respeito pelas diferenças, aos elementos de discriminação, entre outros. Esta centralidade, que nos parece inadequada e desfavorável, impinge um "peso" muito grande a uma única disciplina, quando a literatura indica que o tema tem de ser tratado, nas escolas, de forma transversal, interdisciplinar, com a participação de todos os componentes curriculares. De fato, para a EDH se concretizar é necessária a articulação dos conhecimentos, marcado por um processo de diálogo e de criação de experiências na escola, em geral, e nas salas de aula, em particular.

O trabalho com Educação em Direitos Humanos requer estratégias metodológicas voltadas para o diálogo, privilegiando a atividade e a participação dos alunos em situações reais de vida, que devem ser trazidas para a sala de aula no processo de ensino e aprendizagem.

Duas outras questões devem ser ressaltadas das análises realizadas nos documentos da rede de ensino de Santo André. A primeira é a ausência de referências para as escolas em relação à criação de uma cultura de paz, elemento importante para a criação de um ambiente de liberdade, de tolerância mútua, de solidariedade e de respeito. A segunda, a ausência de diretrizes para o combate ao bullying escolar, questão crescente nas escolas brasileiras e um elemento essencial que motivou a criação de leis (Lei n. 13.185, Lei n. 13.663/18).

Em que pese a presença de algumas diretrizes particularizadas, este quadro de ausências pode obstaculizar a formação dos alunos em relação à Educação em Direitos Humanos. Neste contexto, as escolas podem ter distintas concepções, ideias e projetos para trabalhar o assunto ou, simplesmente, colocá-lo em um segundo plano. Tal processo pode dar origem a oportunidades de aprendizagem, em relação $\mathrm{EDH}$, muito diferentes. De fato, enquanto alguns jovens poderão vivenciar uma cultura de tolerância, de paz, de solidariedade e de respeito aos direitos humanos, outros podem ficar com este direito restrito. Um processo que pode ser caracterizado como discriminação social.

\section{Referências}

ABRAMOVAY, M. Diagnóstico participativo das violências nas escolas: falam os jovens. In: Abramovay, M. (coord.); Castro, M. G.; Silva, A. P. da; Cerqueira, L. Rio de Janeiro: FLACSO - Brasil, OEI, MEC, 2016.

ALMEIDA, C. N.; REIS, H. A educação em direitos bumanos como ferramenta de consolidação e expansão dos direitos humanos. Revista Interdisciplinar em Direitos Humanos, v. 6, n. 1, p. 45-59, 2018. 
AQUINO, J. G. Da (contra)normatividade do cotidiano escolar: problematizando discursos sobre a indisciplina discente. Cadernos de Pesquisa, v. 41, n. 143, 2011.

ATLAS DO DESENVOLVIMENTO HUMANO. Índice de Desenvolvimento Humano Municipal. Disponível em: http:/ / www.atlasbrasil.org.br/ranking. Acesso em: 4 de março de 2019.

BRASIL. Constituição da República Federativa do Brasil. Diário Oficial da União, 5 de outubro de 1988.

BRASIL. Parâmetros Curriculares Nacionais: temas transversais; pluralidade cultural. Ministério da Educação. Secretaria de Educação Fundamental. Brasília, DF: MEC/SEF, 1998.

BRASIL. Declaração universal dos direitos humanos (DUDH). Brasília: Secretaria Especial dos Direitos Humanos, 1998.

BRASIL. SENADO FEDERAL. Lei 10.639, de 09 de janeiro de 2003.

BRASIL. SENADO FEDERAL. Lei 13.010, de 26 de junho de 2014.

BRASIL. SENADO FEDERAL. Lei 13.185, de 06 de novembro de 2015.

BRASIL. SENADO FEDERAL. Lei 13.663, de 14 de maio de 2018.

BRASIL. Comitê Nacional de Educação em Direitos Humanos. Plano Nacional de Educação e Direitos Humanos. Brasília: Secretaria Especial de Direitos Humanos, Ministério da Educação/Ministério da Justiça e Unesco, 2007.

BRASIL. Plano Nacional de Educação em Direitos Humanos. Comitê Nacional de Educação em Direitos Humanos. Brasília: Secretaria Especial dos Direitos Humanos; MEC, 2008.

BRASIL. Parecer CNE/CP n. 7/2010. Diretrizes Curriculares Nacionais para a Educação Básica. Brasília, MEC/CNE, 2010.

BRASIL. Diretrizes Curriculares Nacionais para a Educação em Direitos Humanos. Brasília, MEC/CNE, 2012.

BRASIL. Lei de diretrizes e bases da educação nacional. Lei no 9.394/1996. Brasília, DF: Senado Federal: Coordenação de edições técnicas, 2017. 58 p. Disponível em: http://www2.senado.leg.br/bdsf/id/: 529732/lei_de_diretrizes_e_bases_1ed.pd. Acesso em: 15 jan. 2020.

BRASIL. Base Nacional Comum Curricular: Educação Infantil, Ensino Fundamental e Ensino Médio, 2018. Ministério da Educação. CONSED. Disponível em: http://basenacionalcomum.mec.gov.br/abase Acesso em 26 jan.2020.

CANDAU. V. M. et al. Tecendo a cidadania - oficinas pedagógicas de Direitos Humanos. Petrópolis: Vozes, 1998.

CANDAU, V. M. Educação em direitos humanos: desafios atuais. In: GODOY, Rosa et.al. Educação em Direitos Humanos: fundamentos teórico-metodológicos. João Pessoa: Editora Universitária da UFPB, 2007. 
CANDAU, V. M.: SCAVINO, S. Educação em direitos humanos: concepções e metodologias. In: Ferreira, Lúcia de F.G. et al. (Orgs.). Direitos humanos na educação superior: subsídios para a educação em direitos humanos na pedagogia. João Pessoa: Editora Universitária da UFPB, 2010.

CANDAU, V. M. Professores/as: multiplicadores/as de educação em direitos humanos. sociedade e cultura, v. 16, n. 2, p. 309- 314, jul./dez. 2013.

CHIZZOTTI, A. A Pesquisa Qualitativa em Ciências Humanas e Sociais: evolução e desafios. Revista Portuguesa de Educação, v.16, n. 2, p. 221-236, 2003.

GIL, A. C. Como Elaborar Projetos de Pesquisa. 4ª ed. São Paulo: Atlas, 2017.

GORCZEVSKI, C.; TAUCHEN, G. Educação em Direitos Humanos: para uma cultura da pa\%. Educação, Porto Alegre, v. 31, n. 1, p. 66/74, jan./abr. 2008.

LEME, M. I. da S. Convivência, conflitos e educação nas escolas de São Paulo. São Paulo: Instituto SM para a educação (ISME), 2006.

MELO FILHO, A. M. C. EDUCAÇÃO EM DIREITOS HUMANOS: uma Análise de Livros Didáticos de Lingua Portuguesa do Ensino Médio. Dissertação de Mestrado apresentada para a Universidade Federal de Pernambuco, Recife. 2015.

OLIVEIRA, M. F. Fundamentos Político-educacionais da EDH. IN: Mara Rejane Ribeiro Getúlio Ribeiro. Educaşão em Direitos Humanos e Diversidade Diálogos Interdisciplinares. 2012, p. 573-595.

ORGANIZAÇÃO DAS NAÇÕES UNIDAS (ONU). Declaração Universal dos Direitos Humanos. Janeiro/2009. Disponível em: https://nacoesunidas.org/wpcontent/uploads/2018/10/DUDH.pdf Acesso em 26 jan.2020

ORGANIZAÇÃO DAS NAÇÕES UNIDAS (ONU). Organização das Nações Unidas. O que são os direitos humanos? Disponível em: https://nacoesunidas.org/direitoshumanos/. Acesso em: 05 out. 2020.

ORGANIZAÇÃO DAS NAÇÕES UNIDAS (ONU). Declaração dos Direitos do Homem, 1948. Acesso em: 10 junho 2021. Disponível: http://www.onu-brasil.org.br/documento_ direitoshumanos.php.

SECRETARIA MUNICIPAL DE EDUCAÇÃO DE SANTO ANDRÉ. Documentos Curriculares da Rede Municipal de Ensino de Santo André. Disponível em:

http://santoandre.educaon.com.br/documento-curricular-andreense/. Aceso em 16 de fevereiro de 2019.

SANTOS, E. F. Desafios na Implementação da Proposta Curricular da Educaşão Infantil na percepção dos Assistentes Pedagógicos da Rede Municipal de Santo André. Trabalho Final de Curso apresentado ao Programa de Pós-Graduação em Educação Mestrado Profissional para a obtenção do título de Mestre em Educação. UNSCS.11/02/2020. Disponível em: < http:// repositorio.uscs.edu.br/ > Acesso em 20 nov.2020

SILVA, K. S. Neoliberalismo e Direitos Humanos: Trajetórias opostas. Revista Sequência - Estudos Jurídicos e Politicos, UFSC, Florianópolis, v. 20, n.39, p. 96 - 113, dez. 1999.

SOVERAL, A.; CARBONARI, P. Educação em direitos humanos: sistematização de práticas de educação básica. Passo Fundo: IFIBE - Instituto Superior de Filosofia Berthier, p 19-33, 2011. 